\title{
Safety and immunogenicity of Salmonella typhimurium expressing C-terminal truncated human IL-2 in a murine model
}

This article was published in the following Dove Press journal:

Biologics:Targets \& Therapy

13 March 2010

Number of times this article has been viewed

\author{
Brent Sorenson \\ Kaysie Banton \\ Lance Augustin \\ Sean Barnett \\ Karen McCulloch \\ Joshua Dorn \\ Natalie Frykman \\ Arnold Leonard \\ Daniel Saltzman \\ Department of Surgery, University \\ of Minnesota Medical School, \\ Minneapolis, MN, USA
}

Correspondence: Daniel A Saltzman Department of Surgery, University of Minnesota Medical School, 420 Delaware St., SE, MMC 195, Minneapolis, MN 55455, USA

$\mathrm{Tel}+\mathrm{I} 6126264214$

Fax + I 6126246969

Email saltz002@umn.edu

\begin{abstract}
Salmonella enterica serovar Typhimurium preferentially colonizes tumors in vivo and has proven to be an effective biologic vector. The attenuated S. enterica Typhimurium strain $\chi 4550$ was engineered to express truncated human interleukin-2 and renamed SalpIL2. Previously, we observed that a single oral administration of SalpIL2 reduced tumor number and volume, while significantly increasing local and systemic natural killer (NK) cell populations in an experimental metastasis model. Here we report that in nontumor-bearing mice, a single oral dose of SalpIL2 resulted in increased splenic cytotoxic T and NK cell populations that returned to control levels by 4 weeks post oral administration. Though SalpIL2 was detected in mouse tissues for up to 10 weeks, no prolonged alterations in peripheral blood serum chemistry or complete blood cell counts were observed. Similarly, comparative histopathological analysis of tissues revealed no significant increase in pyogranulomas in SalpIL2-treated animals with respect to saline controls. In Rag-1 knockout mice, which have severely impaired B and T cell function, SalpIL2 reduced growth of hepatic metastases. Furthermore, SalpIL2 altered expression of several proinflammatory cytokines and chemokines in the serum of mice with pulmonary osteosarcoma metastases. These data further suggest that SalpIL2 is avirulent and induces a cell-mediated antitumor response.
\end{abstract}

Keywords: Salmonella Typhimurium, natural killer cells, interleukin-2

\section{Introduction}

Patients diagnosed with distant metastases of colorectal adenocarcinoma and osteosarcoma have $11 \%$ and 30\% 3-year survival rates, respectively. ${ }^{1,2}$ In contrast, patients with localized osteosarcoma or colon cancer achieve nearly 70\% 3-year and 90\% 5-year survival, respectively. ${ }^{1,3}$ Therefore, development of early detection techniques and more efficient tumor-targeting therapies are needed to improve survival in patients with metastatic tumors.

Salmonella enterica serovar Typhimurium is a Gram-negative intracellular facultative anaerobe transmitted via the fecal-oral route. After oral ingestion, Salmonella invades the intestinal epithelia, colonizes Peyer's patches, and enters the lymphatics and bloodstream by infecting inactivated macrophage and dendritic cells. The bacteria then escapes to systemic tissues including the liver, spleen, and lungs. In addition, attenuated $S$. enterica preferentially invade and multiply within tumors relative to normal tissue. ${ }^{4-6}$ We engineered an attenuated strain of $S$. enterica Typhimurium, $\chi 4550$, to express a truncated human interleukin-2 (IL-2) protein and named it SalpIL2. A single oral dose of SalpIL2, in animals with established pulmonary osteosarcoma metastases, significantly reduced tumor burden while increasing pulmonary natural killer (NK) cell 
populations as compared to non-IL2-expressing $S$. enterica and saline controls. ${ }^{7}$ Furthermore, SalpIL2 oral administration prior to tumor injection prevented the establishment of metastatic tumors and increased splenic and hepatic NK cell populations. ${ }^{8,9}$ Although SalpIL2 tracks to established tumors, it is unknown whether its antitumor effect is completely immune cell-mediated or is directly toxic to tumor cells in vivo.

Here we seek to further characterize the antitumor effect of a single oral administration of SalpIL2 in experimental mouse tumor models. In a murine infection model, SalpIL2 was avirulent and immunogenic, and within 16 weeks after oral administration colony-forming units (CFU) were no longer detectable in nontumor tissues, including the spleen, liver and lungs. Oral administration of SalpIL2 resulted in a maximal increase of splenic NK cell populations within 14 days and decreased metastatic hepatic tumor burden in a T cell-independent manner. Lastly, oral administration of SalpIL2 in tumor-burdened animals significantly altered the abundance of several proinflammatory serum cytokines. These data strongly suggest that SalpIL2 is highly immunogenic, reduces tumor burden and tumor-associated systemic inflammation, while increasing proliferation of tumor-targeting cytotoxic NK cells.

\section{Materials and methods}

\section{Tumor cells}

Mouse osteosarcoma K7M2 (ATCC no. CRL-2836) and colon adenocarcinoma MCA-38 cells were maintained and prepared as previously described. ${ }^{7,9}$ All cultured cells were used within 18 passages from the master cell bank and were greater than $90 \%$ viable as determined by trypan blue exclusion.

\section{Bacteria}

The attenuated $S$. enterica Typhimurium strain $\chi 4550$ was a kind gift from Dr. Roy Curtiss III (Washington University, St. Louis, MO). Plasmid constructs with or without a truncated C-terminal human interleukin-2 gene were electroporated into $\chi 4550$ and the resulting strains were named SalpIL2 and Sal-NG, respectively.

\section{Animals}

\section{Bacterial administration}

All animals were orally administered $200 \mu \mathrm{L}$ of Hank's buffered salt solution (HBSS) or HBSS containing $2 \times 10^{8}$ CFU Sal-NG or SalpIL2 and monitored for 15 minutes to ensure the bacteria were not aspirated. All mice were housed under the strict care of the University of Minnesota Research Animal Resources in a biosafety level 2 facility.

\section{Biodistribution}

Six to eight-week-old female C57BL/6 mice were gavage fed either saline or SalpIL2 or Sal-NG. Mice were harvested weekly for 4 weeks to determine tissue toxicity of SalpIL2 or Sal-NG. In an additional experiment, 11016 to 20-weekold female C57BL/6 mice were randomly separated and orally administered either saline or SalpIL2 and sacrificed as described below.

\section{Harvest procedure}

On days 3, 7, 14 and biweekly until week 16, randomly selected groups of $(n=5)$ saline and SalpIL2-treated mice were anesthetized with a ketamine/xylazine (1:2) combination. Animal tissues were aseptically harvested and separated for determination of $S$. enterica $\mathrm{CFU}$ per gram of tissue or placed in $10 \%$ formalin and submitted for independent pathology analysis. The tissues analyzed included the heart, thymus, brain, lung, liver, spleen, stomach, small intestine, large intestine, bone marrow, intra-abdominal lymph nodes and kidneys. Formalin-fixed tissues were examined for pathological signs of Salmonella infection or IL-2 toxicity by Charles River Laboratories, Pathology Associates, Maryland (PAI). For determination of S. enterica CFU, half of each aforementioned tissue was weighed and mechanically minced to a homogenous slurry in $4^{\circ} \mathrm{C}$ phosphate-buffered saline (PBS) with sterile glass stoppers. Bone marrow was collected by aseptic removal and perfusion of the femur with sterile PBS. In addition, urine and feces were aseptically collected from the bladder and large intestine. All tissues and bodily fluids were cultured in triplicate on MacConkey II and Hektoen agar plates overnight.

\section{Serum collection}

Peripheral blood at all experimental endpoints collected from the right atrium of anesthetized animals was analyzed for complete blood count (CBC), centrifuged for serum chemistries or stored at $-20^{\circ} \mathrm{C}$ for cytokine analysis.

\section{Serum chemistries}

Glucose, aspartate aminotransferase (AST), alanine transaminase (ALT), alkaline phosphatase (Alk $\Phi$ ), bilirubin, cholesterol, total protein (TP), albumin, globulin, blood urea nitrogen (BUN), creatinine, phosphorous, calcium, sodium, potassium, chloride, bicarbonate, anion gap and gamma-glutamyl transferase (gamma-GT) serum concentrations were examined by the University of 
Minnesota's Research Animal Resources' in-house veterinary laboratory.

\section{Complete blood cell counts}

White blood cells (WBC), neutrophils (NE), lymphocytes (LY), monocytes (MO), eosinophils (EO), basophils (BA), red blood cells (RBC), mean corpuscular volume (MCV), hemoglobin $(\mathrm{Hb})$, hematocrit (HCT), mean corpuscular hemoglobin $(\mathrm{MCH})$, mean corpuscular hemoglobin concentration (MCHC), red blood cell distribution width (RDW), platelets (PLT), mean platelet volume (MPV), packed cell volume (PCV), and total plasma protein (TPP) were analyzed by the University of Minnesota's Research Animal Resources' in-house veterinary laboratory.

\section{PCR analysis of Salmonella colonies}

Colonies morphologically similar to $S$. enterica Typhimurium were confirmed to be SalpIL2 by polymerase chain reaction (PCR) for the presence of the plasmid containing truncated interleukin-2 sequence. The forward primer 5'-TGAATTG GAAGATCTTCCGG-3' anneals 127 nt upstream from the transcription start site of the truncated IL-2 and the reverse primer 5'-GTTTTGGCGGATGAGAGAAG-3' anneals $4 \mathrm{nt}$ downstream from the truncating stop codon resulting in a PCR product of $587 \mathrm{bp}$. PCR products were run on $2 \%$ agarose gels against no template controls and known SalpIL2 stock as controls to ensure maintenance of plasmid in vivo and identification of the genotype.

\section{Splenic lymphocyte response to Salmonella}

In duplicate experiments, 1006 to 8 -week-old C57BL/6 female mice were orally administered saline, $S a l-N G$, or SalpIL2 as described above. Cohorts of animals $(\mathrm{n}=5)$ were sacrificed 3, 7, 14, 21 and 28 days after oral gavage for collection of splenic mononuclear cells. Lymphocytes were stained with rat antimouse conjugated antibody (BD Pharminogen, San Diego, CA) using previously described methods and identified with a FACScalibur flow cytometer (Becton Dickenson, Grenoble, France) and analyzed with Cell Quest Pro Software (Becton Dickenson, San Jose, CA). ${ }^{9}$ Lymphocyte populations were identified using forward scatter versus side scatter profiles and gated for mononuclear lymphocytes. NK, CD8 ${ }^{+}$ and $\mathrm{CD} 4^{+}$cell populations were identified by single-positive populations based on 10,000-gated events.

\section{Tumor metastasis models}

Six to eight-week-old female Balb/c and Rag-1 ${ }^{-/}$mice were acquired from Harlan Sprague Dawley (Indianapolis, IN). Mice were orally gavaged 7 days prior (prophylactic model) or 3 days after tumor injection (treatment model) with standardized bacterial stocks as previously described. ${ }^{7}$ In triplicate experiments, $2 \times 10^{5} \mathrm{~K} 7 \mathrm{M} 2$ osteosarcoma cells were injected in the left lateral tail vein. Additional mice were sacrificed for hematoxylin and eosin (H\&E) analysis of animals in prophylactic and treatment osteosarcoma models. Aseptically removed lungs were submitted for $H \& E$ analysis by the University of Minnesota's Histopathology core. In the hepatic metastasis model, mice were injected with $5 \times 10^{4}$ MCA-38 colorectal cancer cells as previously described. ${ }^{9}$ Mice were separated into the following groups: 2 saline controls (no tumor injection), 5 C57BL/6 controls, 9 Rag-1 ${ }^{-/}$saline controls, 8 Rag-1 ${ }^{-/-}$Sal-NG, and 10 Rag-1-1/- SalpIL2.

\section{Cytokine analysis}

Serum was collected from mice with K7M2 pulmonary metastasis at the time of sacrifice. Samples were loaded into a 96-well plate and analyzed following manufacturer's guidelines with a Bio-Plex 23-Murine Cytokine Assay (Bio-Rad, Hercules, CA) on the Bio-Plex 200 Array Reader.

\section{Statistical analysis}

Statistical tests were performed with StatView software (v. 5.0.1; SAS Institute, Cary, NC). CFU/cell and serum cytokines in osteosarcoma experiments and hepatic lymphocyte populations and tumor volume in $\operatorname{Rag}-\mathrm{I}^{-/-}$mice were entered for each specimen at the experimental endpoint to calculate the total mean values for each treatment group. Statistical significance between groups were determined by Fisher's exact test. Values from splenic lymphocytes, CBC and serum chemistries were entered for each mouse at the experimental endpoint to calculate the total mean values for each treatment group. Statistical significance between groups was determined by Students' unpaired $t$-test for serum and $\mathrm{CBC}$ and Fisher's exact test for splenic lymphocytes.

\section{Results}

\section{Biodistribution of SalpIL2}

C57BL/6, in contrast to Balb/c mice, have an exaggerated Th-1 cell-mediated immune response and is the genetic background for many transgenic knockout animals including the Rag- $1^{-/}$T-cell knockout strain. ${ }^{10,11}$ Thus, C57BL/6 is a model strain for examining the virulence of an attenuated intracellular pathogen. Salmonella infection appears to be age dependent in C57BL/6 mice, as animals under 24 weeks are significantly more resistant to infection than their aged counterparts. ${ }^{12}$ In this study, 6 to 8 -week-old C57BL/6 mice orally administered Sal-NG and SalpIL2 showed no 
Table I CFU per gram tissue of a single oral gavage of $10^{8}$ CFU of SalpIL2 in naïve 16- to 20 -week-old C57BL/6 mice. Results are mean values from animals with SalpIL2 positive CFU. Numbers in parentheses represent the number of animals out of five with detectable SalpIL2 in the respective tissue. SalpIL2 was not detected in tissue from control animals at any harvest time

\begin{tabular}{|c|c|c|c|c|c|c|c|c|c|c|c|}
\hline Time & $2 \mathrm{~h}$ & $3 d$ & I w & $2 w$ & $4 w$ & $6 w$ & $8 w$ & $10 \mathrm{w}$ & $12 \mathrm{w}$ & $14 w$ & $16 w$ \\
\hline Thymus & $2.67(I)$ & - & - & - & $3.4 \mathrm{I}(\mathrm{I})$ & - & - & - & - & - & - \\
\hline Brain & - & - & $3.04(1)$ & $3.09(1)$ & $2.65(I)$ & - & - & - & - & - & - \\
\hline Stomach & $2.99(3)$ & - & - & - & - & $2.24(1)$ & - & $2.95(1)$ & - & - & - \\
\hline S Intestine & $3.82(2)$ & $3.76(I)$ & - & - & - & - & - & - & - & - & - \\
\hline L Intestine & $4.30(2)$ & - & - & - & - & - & - & - & - & - & - \\
\hline Lymph & $2.28(2)$ & - & $3.34(1)$ & $2.99(2)$ & $3.12(3)$ & $3.93(1)$ & - & $3.97(\mathrm{I})$ & - & - & - \\
\hline Lung & $1.74(1)$ & 4.51 (2) & $3.34(3)$ & $3.56(1)$ & $2.93(3)$ & $2.22(1)$ & - & - & - & - & - \\
\hline Heart & - & $2.24(\mathrm{I})$ & - & $3.45(1)$ & - & - & - & - & - & - & - \\
\hline Kidney & $2.29(1)$ & - & - & - & - & $1.97(1)$ & - & $2.49(\mathrm{I})$ & - & - & - \\
\hline Liver & $1.68(2)$ & $2.68(3)$ & 2.21 (4) & $2.67(2)$ & $2.41(4)$ & $2.29(1)$ & - & $2.01(1)$ & - & - & - \\
\hline Spleen & $2.38(I)$ & 3.26 (3) & $3.39(5)$ & $4.06(4)$ & $4.14(5)$ & $3.40(3)$ & $2.87(3)$ & 3.11 (I) & - & - & - \\
\hline
\end{tabular}

Abbreviations: CFU, colony-forming units; h, hours; d, days; w, weeks.

significant differences in the presence of pyogranulomas, CBC or serum chemistries up to 4 weeks following inoculation (data not shown). We next examined the biodistribution and toxicity of SalpIL2 in 16 to 20 -week-old C57BL/6 mice compared to saline controls over 16 weeks (Table 1). SalpIL2 CFU were recovered from the liver and spleen as early as 2 hours post oral administration and detected in the spleen of all treated animals at the 1-week sacrifice. Detectable SalpIL2 colonies remained high until week 4, after which there was a progressive decrease in the number of positive mice. Except for CFU in the stomach of one animal at weeks 6 and 10, SalpIL2 was cleared from the digestive tract within 1 week. We did not detect SalpIL2 in the bone marrow, urine or blood at any time point during the experiment and it was only observed in the fecal material in a single animal during the first 14 days (data not shown). Animals tested positive for SalpIL2 in the lung for up to 6 weeks, and an increasing number of SalpIL2 CFUs were observed in the lung over time. Acute $\mathrm{CFU}$ concentrations decreased in gastrointestinal tract tissue within one week of oral infection, but remained elevated in organs with major capillary beds (lung, liver, and spleen) or with significant immune involvement (thymus and intra-abdominal lymph nodes). Detection of CFUs in the heart and brain were limited to only one mouse per time point. Except for the intra-abdominal lymph nodes, SalpIL2 CFU concentrations decreased in all tissues by week 6 and CFU were not detected in any animal after week 10 .

\section{Serum and $C B C$}

Oral administration of SalpIL2 increased serum chloride concentration compared to saline controls within 2 hours $(115.33 \mathrm{mmol} / \mathrm{L}$ vs $110.75 \mathrm{mmol} / \mathrm{L}$ respectively; $P<0.05)$
(Figure 1). By day 3, mean platelet volume (MPV) decreased in SalpIL2-treated animals relative to controls $(4.78 \mathrm{fL}$ vs $5.50 \mathrm{fL} ; P<0.01$ ), and the number of platelets (PLT) increased (1053 vs 615; $P<0.05$ ) (Figure 3 ). Also by day 3 , in animals treated with SalpIL2 vs controls: EO increased $(0.054 \mathrm{~K} / \mu \mathrm{L}$ vs $0.002 \mathrm{~K} / \mu \mathrm{L} ; P<0.05)$, MO increased $(0.204 \mathrm{~K} / \mu \mathrm{L}$ vs $0.090 \mathrm{~K} / \mu \mathrm{L} ; P<0.05)$, NE increased $(0.604 \mathrm{~K} / \mu \mathrm{L}$ vs $0.210 \mathrm{~K} / \mu \mathrm{L} ; P<0.0209)$, and $\mathrm{WBCs}$ increased $(3.854 \mathrm{~K} / \mu \mathrm{L}$ vs $2.132 \mathrm{~K} / \mu \mathrm{L} ; P<0.0284)$ (Figure 2 ). By week 4, RDW significantly decreased with SalpIL2 treatment $(0.189 \%$ to $0.202 \% ; P<0.05)$. Although RDW values in SalpIL2-treated animals did not vary between weeks 4 and 6, control values decreased $20 \%$ and by week 6 SalpIL2treated animals had significantly increased RDW relative to controls $(0.194 \%$ vs $0.180 \% ; P<0.01)$ (Figure 3 ), Also in week 6, in animals treated with SalpIL2, MCV decreased (40.2 fL vs $42.7 \mathrm{fL} ; P<0.01$ ) (Figure 3), and the amount of Alk $\phi$ increased $(96.25 \mathrm{U} / \mathrm{L}$ vs $84.33 \mathrm{U} / \mathrm{L} ; P<0.05)$ (Figure 1). In week 8, SalpIL2 treated animals had decreased MCV (39.06 fL vs $41.92 \mathrm{fL} ; P<0.05$ ) (Figure 3) and increased phosphorous $(8.3 \mathrm{mg} / \mathrm{dL}$ vs $5.5 \mathrm{mg} / \mathrm{dL} ; P<0.05$ ) (Figure 1). At week 14, decreases were observed in creatinine $(0.100 \mathrm{mg} / \mathrm{dL}$ vs $0.175 \mathrm{mg} / \mathrm{dL} ; P<0.05)$ and BUN (20 vs $28 ; P<0.01$ ) (Figure 1). Differences in remaining serum and blood chemistries examined were determined to be statistically insignificant.

\section{Histopathology}

Microscopic histopathological analysis revealed that the liver in SalpIL2-treated animals underwent the most changes of all tissues examined. Pyogranulomas defined as aggregations of neutrophils, macrophages and mononuclear 

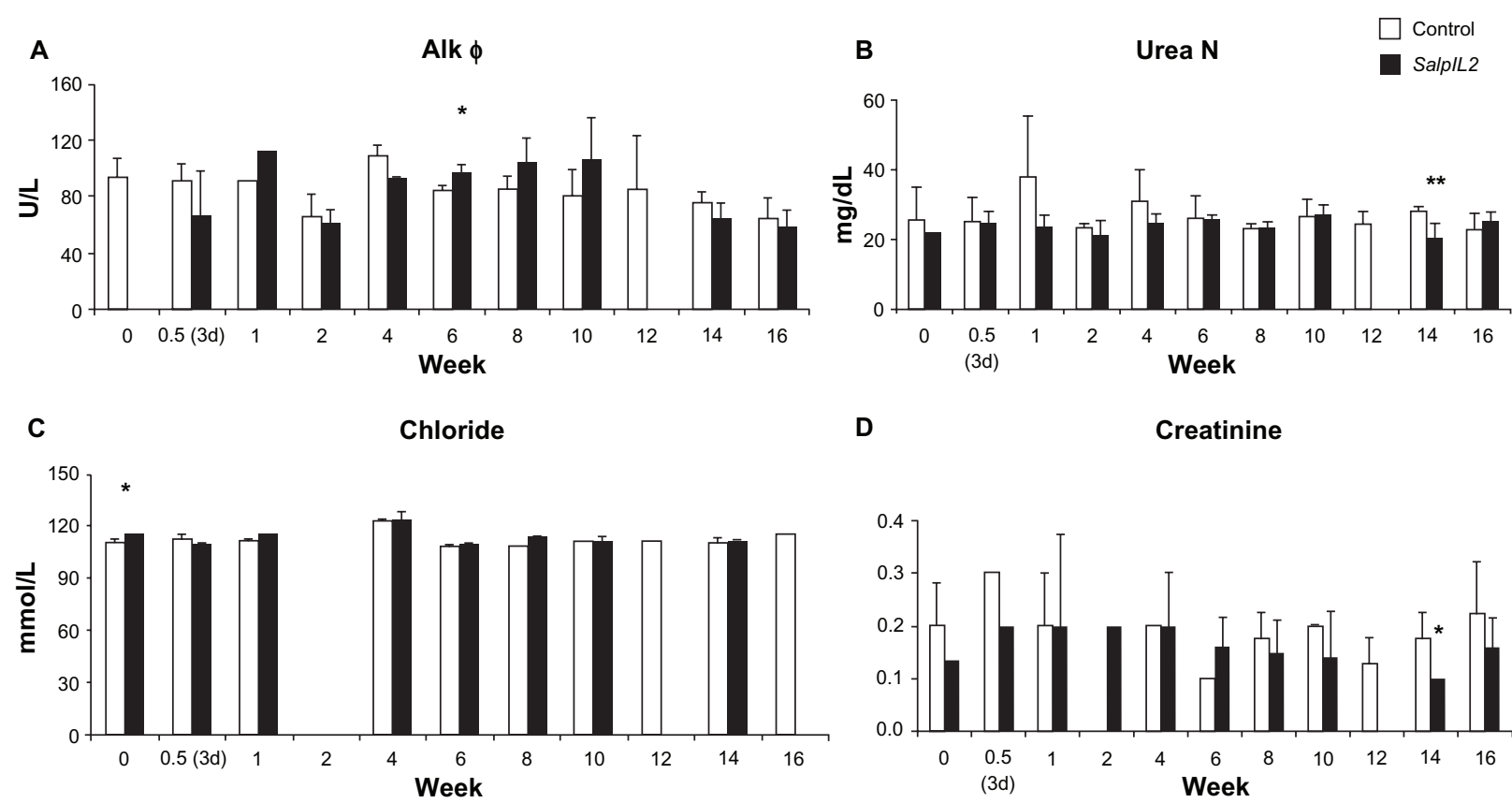

D

Creatinine

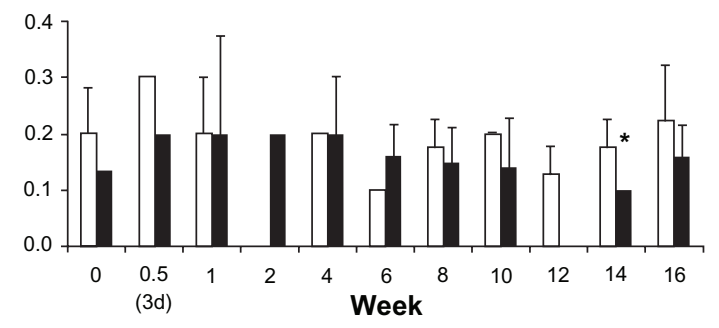

E Phosphorous

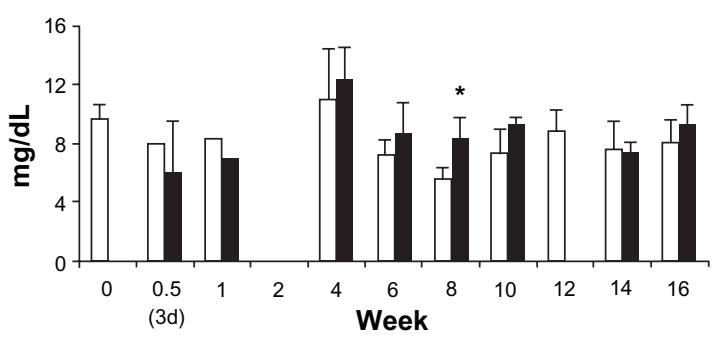

Figure I The effect of a single oral administration of SalpIL2 on mouse serum chemistry. Asterisks indicate statistically significant changes in serum chemistry as determined by unpaired Student's $t$-test. Results presented are mean values from groups of five SalpIL2-treated and five saline control animals.

Notes: Error bars represent one standard deviation. Alkaline phosphatase is denoted as Alk $\phi . * P<0.05, * * P<0.01$.

lymphocytes were present in the liver at 3 and 7 days post oral gavage in two of five mice and classified as mild to moderate. At week 2, three of five livers had mild to moderate pyogranulomas and by week 4 all livers had multifocal pyogranulomas that were classified as mild ( 1 of 5 ) or moderate (4 of 5). At 6 and 8 weeks, four of five livers in each treatment group had multifocal pyogranulomas graded as minimal or mild. At 10 weeks, three of five livers in the SalpIL2 group had mild to moderate pyogranulomas. SalpIL2-treated mice at weeks 12 and 14 had minimal (focal) pyogranulomas with one liver at each time point having multifocal lesions. By week 16, all pyogranulomas in SalpIL2-treated livers were graded as mild or were no longer present in treated mice. In contrast, the saline-treated animals had minimal to mild pyogranulomas in the liver at 6, 10,12 and 16-week sacrifices. Acute Kupffer cell hyperplasia was detected in as many as four of five SalpIL2-treated mice at 1,2 , and 4 weeks post oral gavage and one of five livers had the increase at weeks 6,8 , and 10. No control animals had Kupffer cell hyperplasia.

Spleens from SalpIL2-treated animals displayed increased myelopoiesis from day 3 to week 4 after oral administration, followed by a steady decrease from weeks 6 through 14 . Erythropoiesis was observed in tissues from SalpIL2-treated animals collected at 2 hours and on day 14. Although a rare occurrence, spleens of control animals showed increased erythropoiesis on day 3 and contained multiple mild pyogranlomas at week 4. Similarly, one control lung sample had moderate pyogranulomas present on day 3 and one animal in the 4- and 8-week sacrifices had minimal pulmonary pyogranulomas accompanied by increased pulmonary neutrophils.

Bone marrow tissue displayed mildly increased myelopoiesis as soon as 3 days after administration, moderate myelopoiesis by 2 weeks and mild to obvious myelopoiesis at 4 weeks. Minimal myelopoiesis was present at 6 and 8 weeks in treated animals and continued to decrease until week 14. 

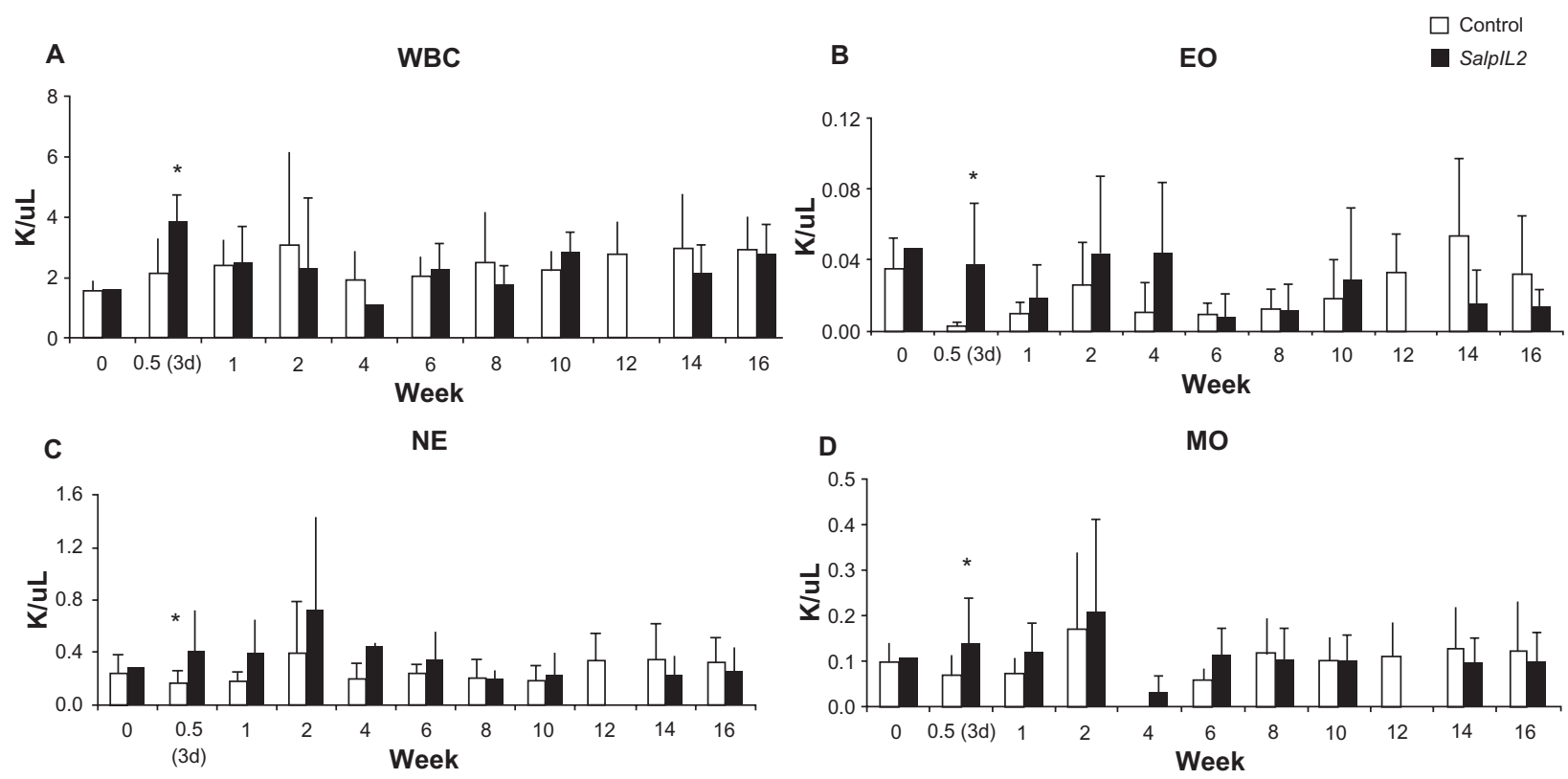

Figure 2 The effect of a single oral administration of SalpIL2 on complete blood cell counts. Asterisks indicate differences determined to be statistically significant by unpaired Student's $t$-test. White blood cells (WBC), neutrophils (NE), monocytes (MO), eosinophils (EO). Results presented are mean values from groups of five SalpIL2-treated and five saline control animals.

Notes: Error bars represent one standard deviation. $* P<0.05$.

In one control animal at 10 weeks, there was marked histolytic cell infiltration of the bone marrow. Minimal to moderate acute inflammation in the submucosa was observed in the stomachs of the SalpIL2-treated animals. In contrast, control animals showed decreased inflammation in the stomach during this period, and inflammation was absent in all animals by week 12. Intra-abdominal lymph nodes had minimal to moderate increased reticuloendothelial cells in the majority of treated mice at weeks 6 and 8 , and in 1 treated animal at all other time points. Four control animals also
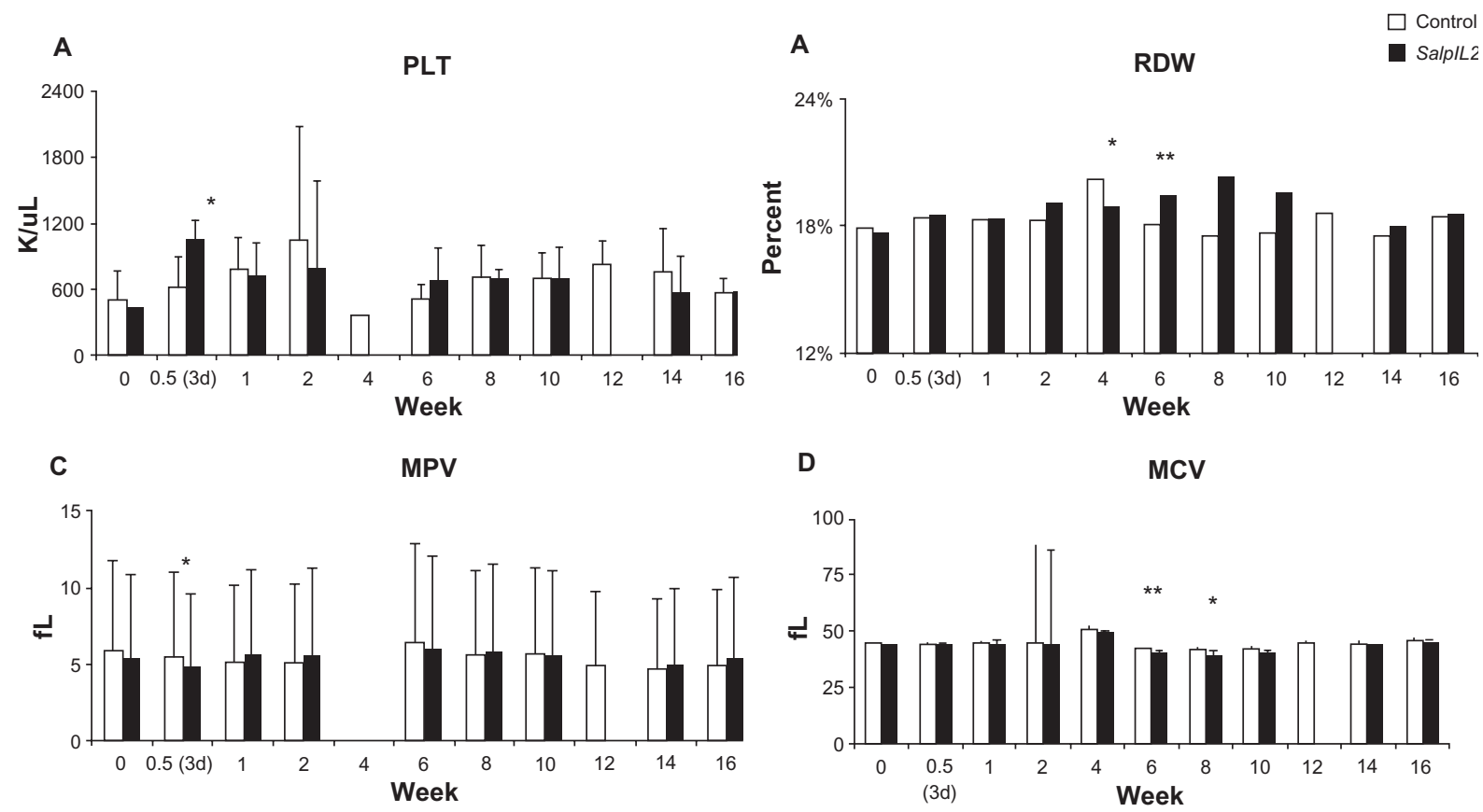

Figure 3 The effect of a single oral administration of SalpIL2 on blood cell phenotype. Mean corpuscular volume (MCV), red blood cell distribution width (RDW), platelet (PLT) and mean platelet volume (MPV) average values are from groups of five SalpIL2-treated and five control animals per time point.

Notes: Error bars represent one standard deviation. Differences determined to be statistically significant by unpaired Student's $t$-test are indicated by asterisks. $* P<0.05$, $* * P<0.01$. 
had reticuloendothelial cell hyperplasia. In the brain, two SalpIL2-treated mice in the 4-week group had mild, multifocal, lymphocytic infiltrates in the meninges. One of these mice had minimal cerebral cortical lymphocytic perivascular cuffing. Microscopic lesions were not observed in the thymus, intestines, heart, or kidney in SalpIL2-treated animals.

\section{Splenic lymphocyte response to SalpIL2}

Animals orally administered SalpIL2 had an increased splenic NK $1.1^{+}$cell population by day 7 which remained elevated on days $14(P<0.01)$ and 21 and returned to basal level by day 28 (Figure 4A). A significant increase in $\mathrm{CD}^{+} \mathrm{T}$ cells $(P<0.001)$ on day 3 was observed followed by a return to baseline by day 7 (Figure 4B). SalpIL2 did not significantly alter the proportion of $\mathrm{CD}^{+} \mathrm{T}$ cells over the 28 -day period (Figure 4C).

\section{A}
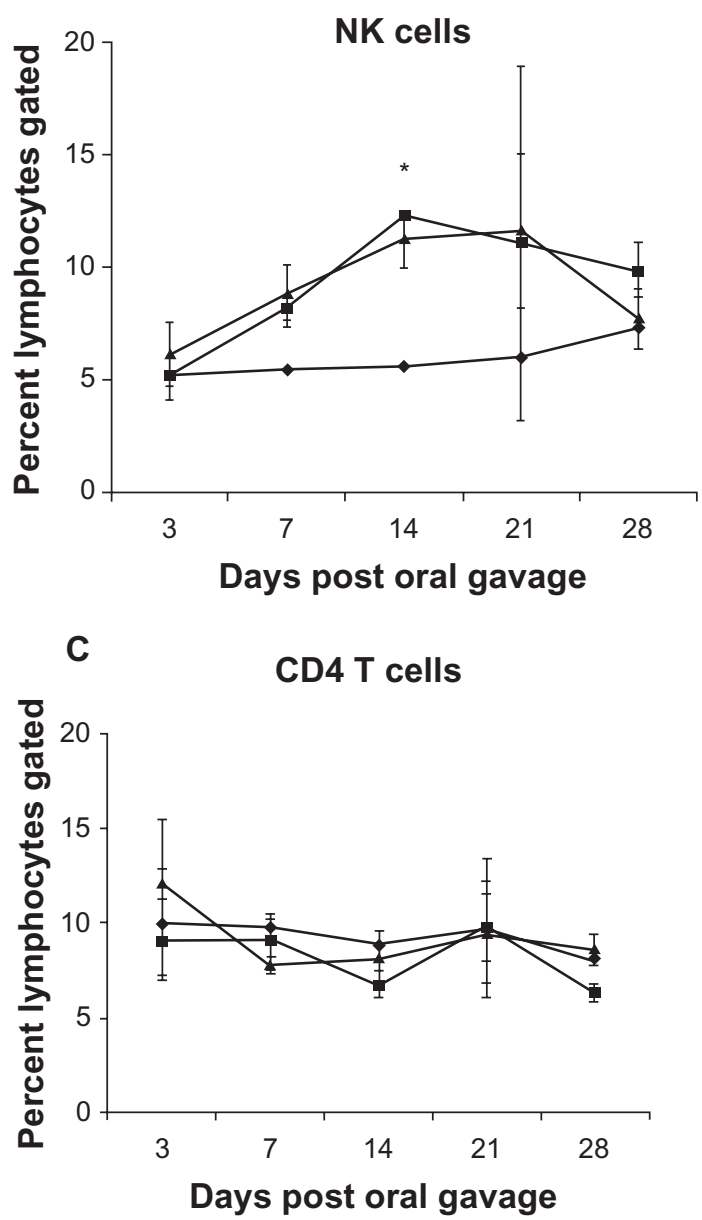

\section{Hepatic metastasis model in Rag- I-}

To elucidate the role of cytotoxic T cells in the SalpIL2 antitumor response, we used $\mathrm{Rag}-1^{-/}$mice, which do not have mature B or T cells, in an experimental hepatic metastasis model. A single oral dose of Sal-NG or SalpIL2 significantly decreased tumor volume with respect to saline controls $(P<0.001$; Figure 5A). Furthermore, compared to saline controls and Sal-NG, SalpIL2 significantly increased hepatic NK cell populations detected by flow cytometry $(P<0.001$ and $P<0.05$ respectively; Figure 5B).

\section{Serum cytokine analysis in experimental osteosarcoma treatment model}

The K7M2 murine osteosarcoma cell line was derived and characterized from spontaneous pulmonary metastases in Balb/c mice. ${ }^{13}$ Using an experimental lung metastasis model

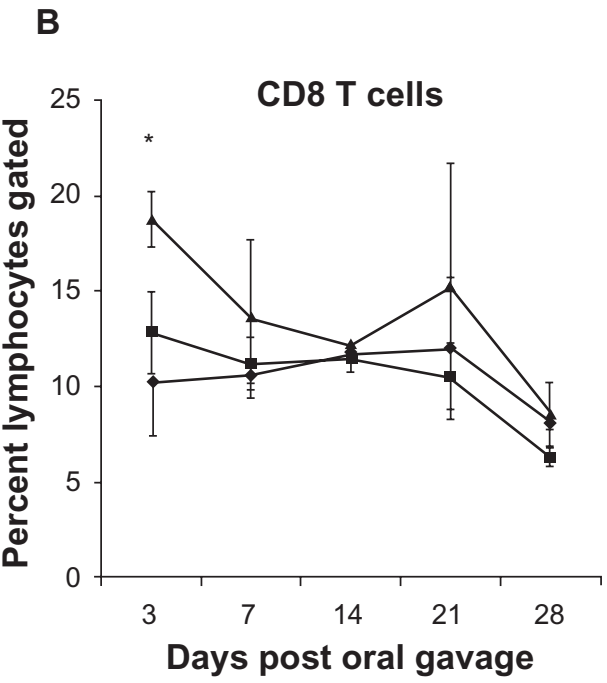

Figure 4 Natural killer (NK) cells and cytotoxic T lymphocytes are significantly increased in the acute systemic immune response to SalpIL2. NK cells (NK I.I) and cytotoxic T cells $\left(C D 8^{+}\right)$populations are significantly increased in response to SalplL2. Helper T cells $\left(C D 4^{+}\right)$populations are not significantly affected by a single oral administration of $2 \times 10^{8} \mathrm{CFU}$ of SalpIL2 or Sal-NG.

Notes: Results from triplicate experiments presented as \pm standard error of mean, were determined to be statistically significant by unpaired Fisher's exact test and indicated by asterisks. $* P<0.05$. 


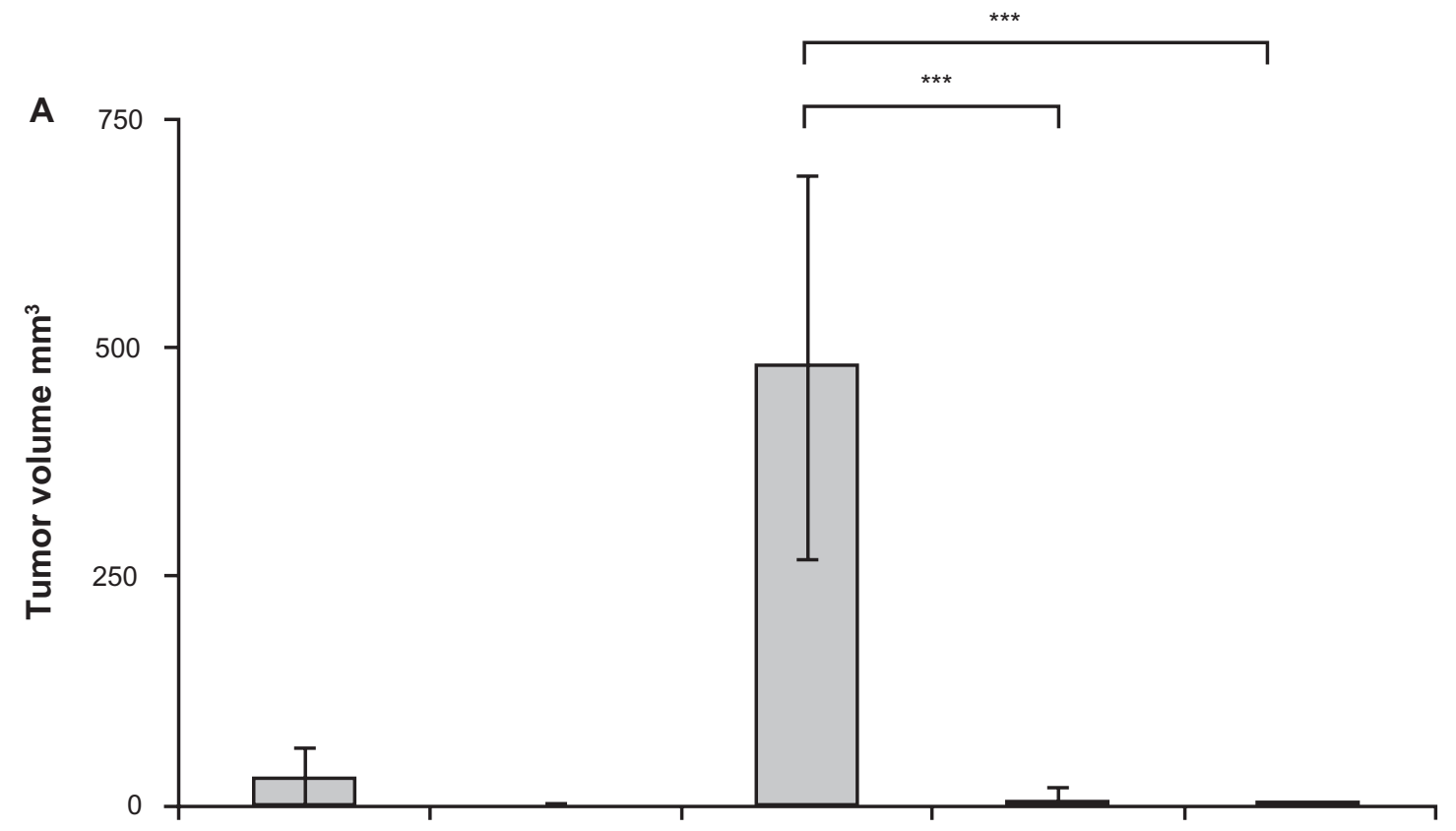

B

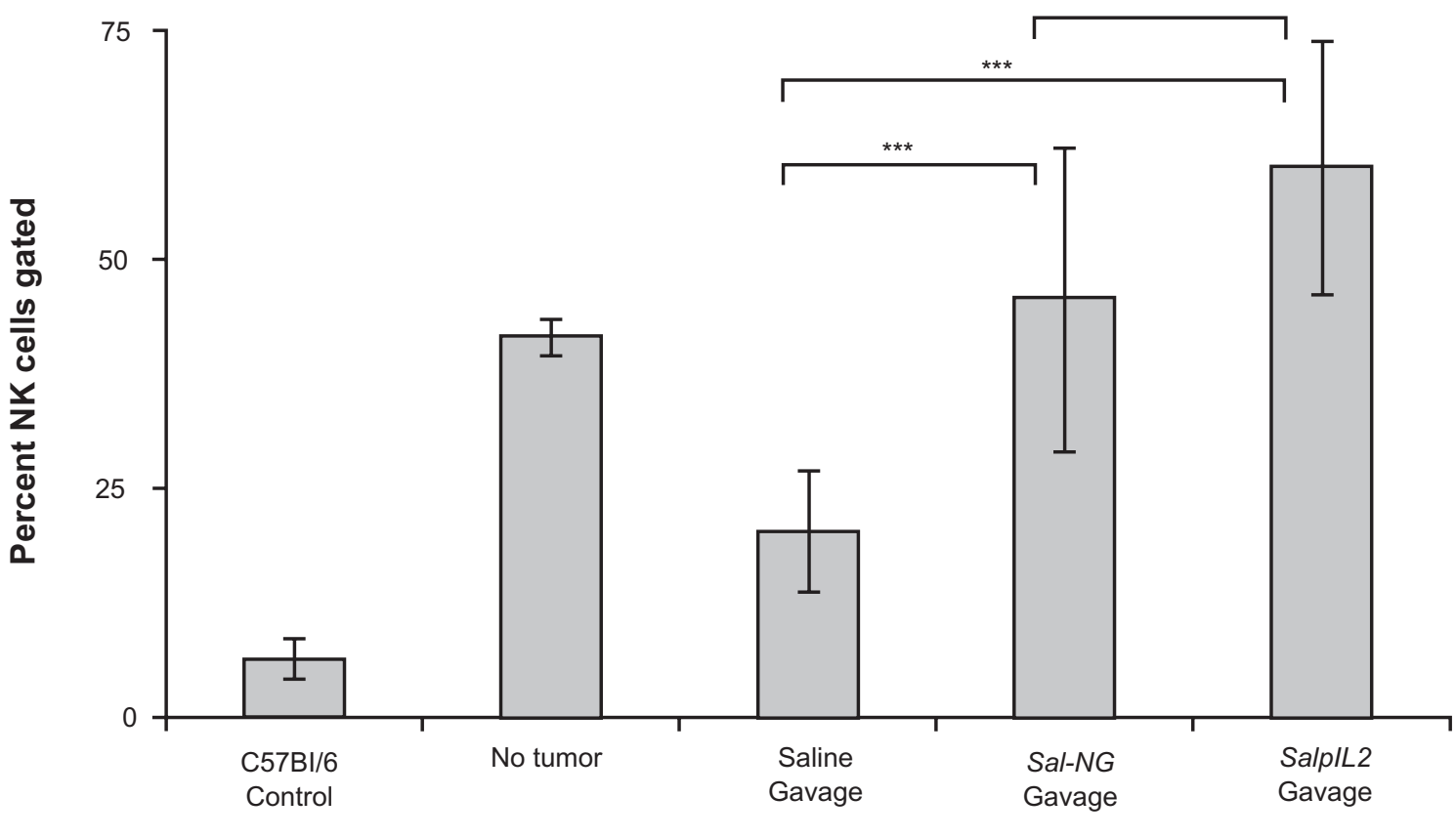

$\operatorname{Rag} 1^{-1-}$

Figure 5 SalpIL2 antitumor effect is independent of cytotoxic T lymphocytes. SalpIL2 increases NK cell population and reduces the macroscopic volume of hepatic metastases in Rag- $I^{-1-}$ mice, which have significantly suppressed T lymphocyte populations.

Notes: Results from one representative experiment shown, $\mathrm{N}=7$. $* \mathrm{P}<0.05$, $* * * p<0.001$.

that produces macroscopic lesions isolated to the lung, we analyzed sera from animals at 3-weeks post tumor injection. Serum cytokines in the treatment model were largely not significantly affected by oral administration of SalpIL2 or Sal-NG. Granulocyte colony-stimulating factor (G-CSF) was significantly increased from a control mean of $45.7 \mu \mathrm{g} / \mathrm{mL}$ to $107.7 \mu \mathrm{g} / \mathrm{mL}(P<0.05)$ in $S a l-N G$ and $114.1 \mu \mathrm{g} / \mathrm{mL}$ $(P<0.05)$ in SalpIL2 (Figure 6C). In addition, Sal-NG treated mice displayed $65 \%$ increase in IL-12p40 $(P<0.05)$ whereas SalpIL2 treated mice did not display a significant 


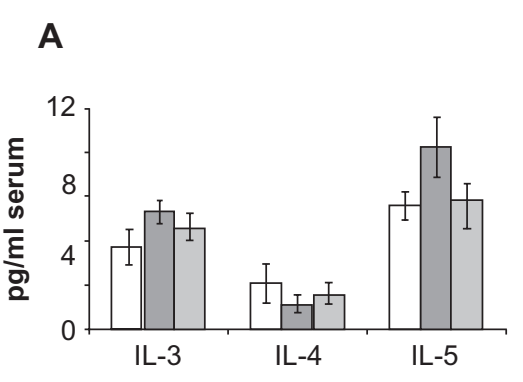

C

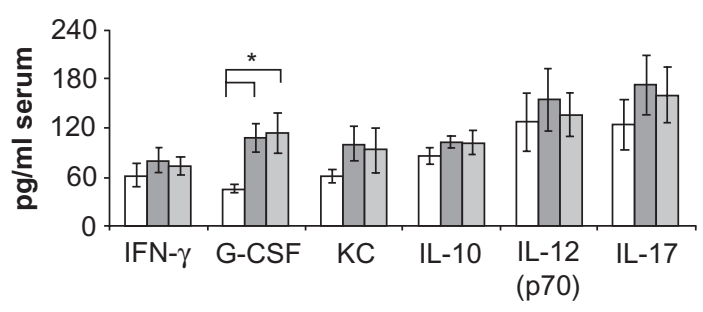

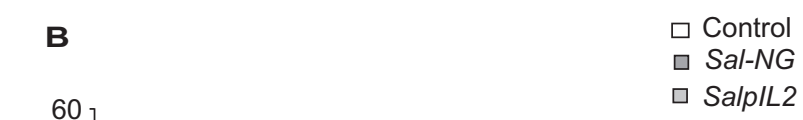

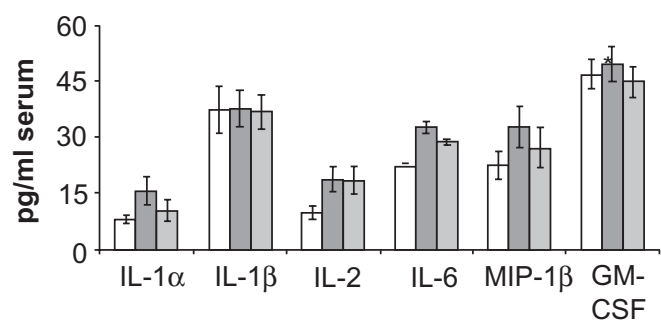

D

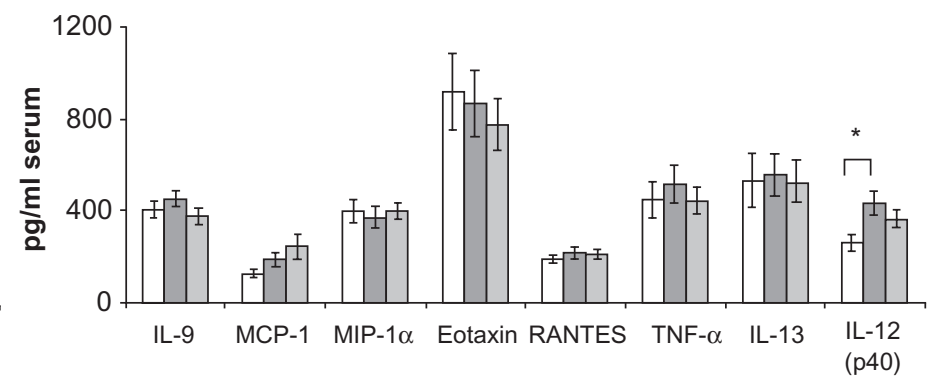

Figure 6 Oral inoculation of Salmonella alters serum cytokines during treatment of metastatic osteosarcoma. SalpIL2, but not Sal-NG significantly increases serum G-CSF with respect to saline controls $(P<0.05$ and $P=0.276$, respectively).

Notes: Results presented as SEM from triplicate experiments. *p $<0.05$.

Abbreviation: G-CSF, granulocyte colony-stimulating factor.

increase in IL-12p40 (Figure 6D). Systemic IL-2 was not significantly increased with SalpIL2 or Sal-NG oral gavage with respect to saline controls (Figure 6B).

\section{Serum cytokine analysis in experimental prophylactic model}

In the prophylactic model of pulmonary metastasis, several systemic cytokines were significantly lower in $\mathrm{Sal}-N G$ and SalpIL2 groups than in saline controls. Sal- $N G$ significantly lowered IL-1 $\beta(P<0.01)$, KC $(P<0.0257)$, and MCP-1 $(P<0.001)$ with respect to control animals (Figure 7). SalpIL2 significantly decreased systemic IL-1 $\beta(P<0.001)$, IL-3 $(P<0.0346)$, KC $(P<0.01)$, MCP-1 $(P<0.001)$, MIP-1 $\beta(P<0.05)$, and RANTES $(P<0.05)$ compared to saline controls.

\section{Discussion}

Salmonella enterica serovar Typhimurium is a Gramnegative intracellular facultative anaerobe transmitted via the fecal-oral route. Upon oral administration, Salmonella migrate to the gastrointestinal tract and colonize lymphoid sections of the small intestine, called Peyer's patches. In addition, intraepithelial dendritic cells provide a route for Salmonella to gain access to underlying tissues and other innate immune cells, thus circumventing the barrier provided by the intestinal epithelium. ${ }^{14}$ Salmonella-infected dendritic cells then migrate to the mesenteric lymph nodes for antigen processing. ${ }^{15}$ Apoptosis of infected macrophage and dendritic cells during their progression through the liver and spleen result in preferential colonization of these organs. ${ }^{16}$ Recent evidence suggests $S$. enterica's survival in hepatic phagocytes includes the formation of a foci, release by necrosis or apoptosis, and invasion of surrounding cells that results in a new foci from a single bacteria. ${ }^{17,18} S$. enterica's colonization of major organs and tissues may persist for up to a period of 4 to 6 months as a result of its ability to reside within an endosome as a facultative intracellular bacteria. ${ }^{19}$ $S$. enterica Typhimurium is an attractive delivery vector for intra-tumoral expression of cytokines or antigenic molecules from viruses, bacteria, and some parasites in various animal models ${ }^{20-26}$ Methods of Salmonella administration in cancer models varying from the oral route to intra-tumor or intravenous injections have been shown to be efficacious. ${ }^{27-29}$ During our investigations we have examined the safety and efficacy of a single oral dose of the attenuated $S$. enterica Typhimurium $\chi 4550$ in reducing tumor burden in mice. The $\chi 4550$ strain is an adenylate cyclase, cyclic adenosine monophosphate receptor protein and aspartate semialdehyde dehydrogenase deletion mutant that does not express a functional flagella. ${ }^{30}$ Oral administration of Salmonella may be 
A

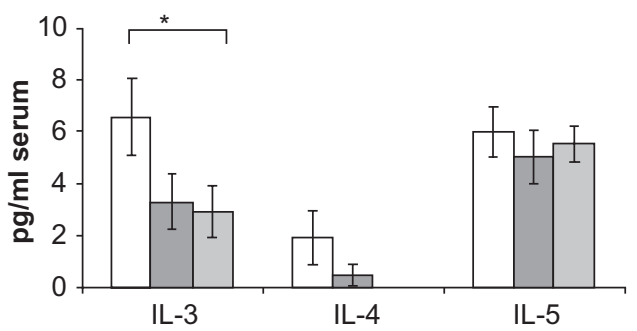

C

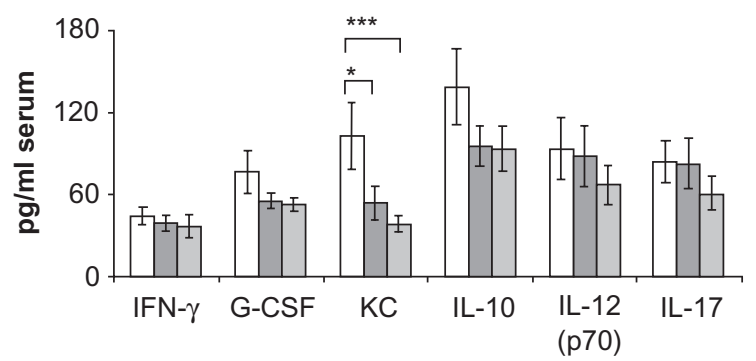

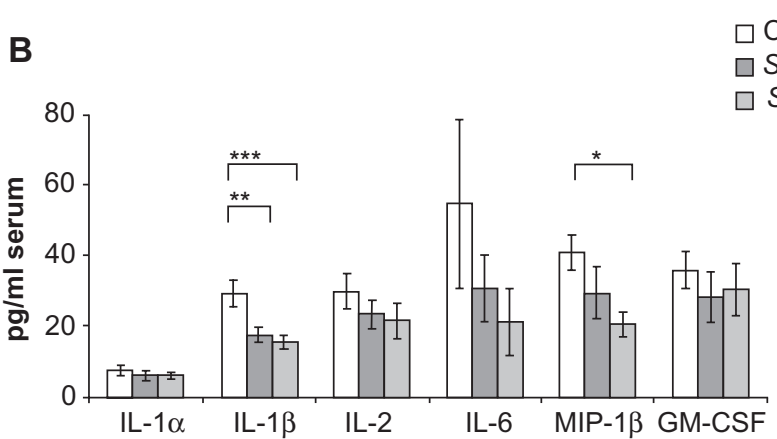

$\square$ Sal-NG

$\square$ SalpIL2

Figure 7 Oral inoculation of Salmonella alters serum cytokines during the prevention of metastatic osteosarcoma. Sal-NG significantly lowers IL-I $\beta$ ( $P<0.0 \mathrm{I})$, KC $(P<0.05)$ and MCP-I $(P<0.00 \mathrm{I})$ with respect to control animals. SalpIL2 significantly decreases systemic IL-I $\beta(P<0.00 \mathrm{I})$, IL-3 $(P<0.05)$, KC $(P<0.0 \mathrm{I})$, MCP-I $(P<0.00 \mathrm{I}), \mathrm{MIP}-\mathrm{I} \beta$ $(P<0.05)$, and RANTES $(P<0.05)$ as compared to saline controls. Notes: $* P<0.05$, $* * P<0.01$, $* * * P<0.001$.

advantageous over intravenous delivery by allowing for use of standardized bacterial glycerol stocks and stimulation of both the systemic and mucosal immunity against intracellular pathogens. As argued by Belyakov and Ahlers, activating intraepithelial dendritic cells at mucosal surfaces produces a more robust response to intracellular pathogens including Salmonella. ${ }^{31}$ We have chosen to examine the safety and efficacy of a single oral dose in our models to reduce the potential inhibitory effects of the secretory IgA immune response against multiple Salmonella administrations. ${ }^{32}$ In prior investigations, a single oral dose of $\chi 4550$ engineered to express a human IL-2 activated NK cells against metastatic hepatic malignancies. ${ }^{9,26,33}$

Here we examined the antitumor mechanism of S. enterica expressing a C-terminal truncated human IL-2 gene. Supporting the pathological finding of a mild inflammatory response to a single oral administration of SalpIL2, splenic mononuclear lymphocytes were increased significantly within the first 7 days of oral administration, but returned to levels similar to control animals by week 4 . Furthermore, oral SalpIL2 inoculation resulted in sporadic increases of inflammatory cells determined by $\mathrm{CBC}$ that gradually decreased as the study progressed. The MPV was decreased following SalpIL2 administration, while the total number of platelets present in the blood nearly doubled, likely due to hematopoietic stimulation in the spleen and bone marrow. White blood cells, eosinophils, monocytes and neutrophils were all increased in the first 2 weeks consistent with concurrent infection. Recovery of SalpIL2 CFU was largely restricted to the liver and spleen and analysis of serum chemistries demonstrated no difference in liver or spleen function between control and SalpIL2-treated animals throughout the experiment. Some evidence of hepatic stress was expected as evidenced by the rise in Alk $\phi$. Slight increases in Alk $\phi$ at the week 6 sacrifice and normal bilirubin throughout demonstrate the ability of the infected animal to maintain normal liver enzymatic function despite mild hepatitis resulting from SalpIL2 infection. Acute increases in serum chloride were perceived to be a result of the gavage media. Renal function was determined to be unaffected as SalpIL2 administration resulted in only a slight decrease in serum BUN and creatinine concentrations at week 14 and a 
slight increase of phosphorous at week 8. In some animals the volume of blood collected was not sufficient to examine all of the possible serum chemistry. Therefore some chemistry was unable to be examined at every sacrifice time point. Despite this limitation, we had a sufficient number of mice per group to determine the general systemic affects of a single oral dose of SalpIL2. Most importantly no SalpIL2-treated animal had detectable CFUs after 10 weeks of infection or displayed outward signs of morbidity, demonstrating the ability of the bacteria to be cleared without antibiotic treatment.

Based on these results, SalpIL2 did not produce a virulent disease state in mice. We were unable to demonstrate morbidity associated with mild hepatitis, or any significant organ dysfunction. The treatment and control animals maintained food consumption within normal established limits. Although a few SalpIL2-treated mice developed meningitis and cerebritis, this observation was isolated to a single cage. It is unclear whether gavage technique or cage conditions may have resulted in SalpIL2 infection of the central nervous system in those animals. Although the natural mode of Salmonella infection is fecal-oral, we were only able to culture SalpIL2 from the stool in one mouse over all time points. This may be a result of the innocula load or attenuation of SalpIL2.

Oral administration of SalpIL2 did not create detectable systemic toxicity that may be cytotoxic to tumors in mice at any time point. Moderate increases in systemic NK and acute $\mathrm{CD}^{+} \mathrm{T}$ cell populations strongly suggest SalpIL2's antitumor mechanism is cell-mediated tumor toxicity. As we reported previously, in a pulmonary metastasis model SalpIL2, but not Sal-NG, significantly increased NK but not CD8 ${ }^{+}$ T cells in the lung relative to saline controls. ${ }^{7}$ Furthermore, depletion of liver NK cells and $\mathrm{CD}^{+} \mathrm{T}$ cells, but not $\mathrm{CD}^{+}$ $\mathrm{T}$ cells and Kupffer, cells abrogated the antitumor effect of $S$. enterica species. ${ }^{26}$ Taken together, these data would suggest that although both SalpIL2 and Sal-NG can induce systemic NK cell proliferation, SalpIL2 is more efficient at attracting NK cells to distant tissues to direct an antitumor response. Because $S$. enterica preferentially tracks to and multiplies within tumors, biodistribution of SalpIL2 in tumor bearing animals may be augmented. Persistence of SalpIL2 in tumors may prolong colonization of other tissues. However, mortality of animals with tumor significantly hinders any prolonged study on the differences in tumor-dependent SalpIL2 distribution.

To further elucidate the role of the immune system in SalpIL2's antitumor response, we used Rag-1 deficient mice that have severely depressed B and T cells, including tumor-supportive regulatory $\mathrm{T}$ cell populations. NK cells lacking rearranged $\mathrm{T}$ cell receptors develop in the bone marrow but function and develop normally in Ragl deficient mice. ${ }^{11}$ Both Salmonella-treated groups significantly decreased tumor volume in a B and T-cell independent manner. SalpIL2, however, had significantly higher hepatic NK cell populations as compared to Sal-NG and saline controls. In animals with established pulmonary metastases, Salmonella-treatment increased expression of G-CSF, a chemokine that promotes monocyte activation and migration into tissues. These data suggest a strong cytotoxic immune response in the treatment animals. Most evident, in mice where tumors were introduced after Salmonella was administered, expression of several proinflammatory chemokines was significantly reduced. However, these observations may be due to the decreased tumor burden in the animal and may not be reflective of the local cytokine environment of the tumor and warrant further study.

$S$. enterica Typhimurium tumor vaccines have become more prevalent in recent years. Many investigators have determined the efficacy of their vaccines through the injection of $S$. enterica Typhimurium directly into the tumor or through intravenous delivery. ${ }^{34,35}$ Administration of these $S$. enterica strains has been encouragingly efficacious in murine primary tumor models. S. enterica antigen vaccines, however, are dependant on homogenous tumor expression of the antigen to be effective against metastatic tumors. ${ }^{27}$ Investigators have shown intravenous administration of attenuated $S$. enterica to be safe in primates and humans in phase I clinical trials. ${ }^{36,37}$ In our investigations, oral administration of SalpIL2 not only localized to the liver, spleen and pulmonary tissues, but also elicited a robust local and systemic NK cell response that was independent of tumor type or animal strain. In our pulmonary metastases model, osteosarcoma metastases formed clearly defined nodules and linear aggregates of invasive tumor cells centered around the pleura. ${ }^{7}$ Mononuclear infiltrate in SalpIL2-treated animals was positively correlated with a reduction in tumor burden and interpreted to represent tumor regression. Hence, the presence of mononuclear cell infiltrates appears to be an integral factor in the reduction of SalpIL2-treated tumors in vivo. Although oral administration induced a mild inflammatory response, these data strongly suggest SalpIL2 is avirulent, immunogenic, and induces a robust NK cell-mediated antitumor response.

\section{Acknowledgments}

The experiments detailed in this article were funded in part by the Arnold S Leonard Cancer Research Fund. We 
acknowledge the University of Minnesota's Cancer Center's Histopathology Core for their slide preparation of histological samples. We thank Gerry O'Sullivan of the University of Minnesota Pathology Lab and Lucas H Brennecke, D.V.M. of Charles River Laboratories, Pathology Associates, Maryland (PAI), for expert, independent third-party histological analysis. We also acknowledge the assistance of the Flow Cytometry Core Facility of the University of Minnesota Cancer Center, a comprehensive cancer center designated by the National Cancer Institute, supported in part by P30 CA77598.

\section{Disclosures}

BS, AL, and DS are stockholders in Botanic Oil Innovation. All other authors certify that he or she have no commercial associations that may pose a conflict of interest in connection with this manuscript.

\section{References}

1. Horner MJ, Ries LAG, Krapcho M, et al. SEER Cancer Statistics Review, 1975-2006, based on November 2008 SEER data submission, posted to the SEER Website, 2009. Bethesda, MD: National Cancer Institute; 2009. Available from: http://seer.cancer.gov/csr/1975_2006/. Accessed on December 10, 2009.

2. Ferguson WS, Harris MB, Goorin AM, et al. Presurgical window of carboplatin and surgery and multidrug chemotherapy for the treatment of newly diagnosed metastatic or unresectable osteosarcoma: Pediatric Oncology Group Trial. J Pediatr Hematol Oncol. 2001;23(6):340-348.

3. Longhi A, Errani C, De Paolis M, Mercuri M, Bacci G. Primary bone osteosarcoma in the pediatric age: state of the art. Cancer Treat Rev. 2006;32(6):423-436.

4. Bermudes D, Low B, Pawelek J. Tumor-targeted Salmonella. Highly selective delivery vectors. Adv Exp Med Biol. 2000;465:57-63.

5. Soto LJ 3rd, Sorenson BS, Nelson BW, Solis SJ, Leonard AS, Saltzman DA. Preferential proliferation of attenuated Salmonella typhimurium within neuroblastoma. J Pediatr Surg. 2004;39(6): 937-940; discussion 937-940.

6. Kasinskas RW, Forbes NS. Salmonella typhimurium specifically chemotax and proliferate in heterogeneous tumor tissue in vitro. Biotechnol Bioeng. 2006;94(4):710-721.

7. Sorenson BS, Banton KL, Frykman NL, Leonard AS, Saltzman DA. Attenuated Salmonella typhimurium with IL-2 gene reduces pulmonary metastases in murine osteosarcoma. Clin Orthop Relat Res. 2008;466(6):1285-1291.

8. Sorenson BS, Banton KL, Frykman NL, Leonard AS, Saltzman DA. Attenuated Salmonella typhimurium with interleukin 2 gene prevents the establishment of pulmonary metastases in a model of osteosarcoma. J Pediatr Surg. 2008;43(6):1153-1158.

9. Soto LJ 3rd, Sorenson BS, Kim AS, Feltis BA, Leonard AS, Saltzman DA. Attenuated Salmonella typhimurium prevents the establishment of unresectable hepatic metastases and improves survival in a murine model. J Pediatr Surg. 2003;38(7):1075-1079.

10. Mills CD, Kincaid K, Alt JM, Heilman MJ, Hill AM. M-1/M-2 macrophages and the Th1/Th2 paradigm. J Immunol. 2000;164(12): 6166-6173.

11. Mombaerts P, Iacomini J, Johnson RS, Herrup K, Tonegawa S, Papaioannou VE. RAG-1-deficient mice have no mature B and T lymphocytes. Cell. 1992;68(5):869-877.
12. Ren Z, Gay R, Thomas A, et al. Effect of age on susceptibility to Salmonella Typhimurium infection in C57BL/6 mice. J Med Microbiol. 2009;58(Pt 12):1559-1567.

13. Khanna C, Prehn J, Yeung C, Caylor J, Tsokos M, Helman L. An orthotopic model of murine osteosarcoma with clonally related variants differing in pulmonary metastatic potential. Clin Exp Metastasis. 2000;18(3):261-271.

14. Rescigno M, Urbano M, Valzasina B, et al. Dendritic cells express tight junction proteins and penetrate gut epithelial monolayers to sample bacteria. Nat Immunol. 2001;2(4):361-367.

15. Vazquez-Torres A, Jones-Carson J, Baumler AJ, et al. Extraintestinal dissemination of Salmonella by CD18-expressing phagocytes. Nature. 1999;401(6755):804-808

16. Tsolis RM, Kingsley RA, Townsend SM, Ficht TA, Adams LG, Baumler AJ. Of mice, calves, and men. Comparison of the mouse typhoid model with other Salmonella infections. Adv Exp Med Biol. 1999;473:261-274.

17. Sheppard M, Webb C, Heath F, et al. Dynamics of bacterial growth and distribution within the liver during Salmonella infection. Cell Microbiol. 2003;5(9):593-600.

18. Grant AJ, Sheppard M, Deardon R, et al. Caspase-3-dependent phagocyte death during systemic Salmonella enterica serovar Typhimurium infection of mice. Immunology. 2008;125(1):28-37.

19. Dunlap NE, Benjamin WH Jr, McCall RD Jr, Tilden AB, Briles DE. A 'safe-site' for Salmonella typhimurium is within splenic cells during the early phase of infection in mice. Microb Pathog. 1991;10(4):297-310.

20. Chou CK, Hung JY, Liu JC, Chen CT, Hung MC. An attenuated Salmonella oral DNA vaccine prevents the growth of hepatocellular carcinoma and colon cancer that express alpha-fetoprotein. Cancer Gene Ther. 2006;13(8):746-752.

21. Hormaeche CE. Live attenuated Salmonella vaccines and their potential as oral combined vaccines carrying heterologous antigens. J Immunol Methods. 1991;142(1):113-120.

22. Huang Y, Hajishengallis G, Michalek SM. Induction of protective immunity against Streptococcus mutans colonization after mucosal immunization with attenuated Salmonella enterica serovar typhimurium expressing an S. mutans adhesin under the control of in vivo-inducible nirB promoter. Infect Immun. 2001;69(4):2154-2161.

23. Xu C, Li ZS, Du YQ, et al. Construction of recombinant attenuated Salmonella typhimurium DNA vaccine expressing $\mathrm{H}$ pylori ureB and IL-2. World J Gastroenterol. 2007;13(6):939-944.

24. Saltzman DA, Heise CP, Hasz DE, et al. Attenuated Salmonella typhimurium containing interleukin-2 decreases MC-38 hepatic metastases: a novel anti-tumor agent. Cancer Biother Radiopharm. 1996;11(2):145-153.

25. Saltzman DA, Katsanis E, Heise CP, et al. Patterns of hepatic and splenic colonization by an attenuated strain of Salmonella typhimurium containing the gene for human interleukin-2: a novel anti-tumor agent. Cancer Biother Radiopharm. 1997;12(1):37-45.

26. Saltzman DA, Katsanis E, Heise CP, et al. Antitumor mechanisms of attenuated Salmonella typhimurium containing the gene for human interleukin-2: a novel antitumor agent? J Pediatr Surg. 1997;32(2):301-306.

27. Nishikawa $H$, Sato E, Briones G, et al. In vivo antigen delivery by a Salmonella typhimurium type III secretion system for therapeutic cancer vaccines. J Clin Invest. 2006;116(7):1946-1954.

28. Loeffler M, Le'Negrate G, Krajewska M, Reed JC. Attenuated Salmonella engineered to produce human cytokine LIGHT inhibit tumor growth. Proc Natl Acad Sci U SA. 2007;104(31):12879-12883.

29. Saltzman DA. Cancer immunotherapy based on the killing of Salmonella typhimurium-infected tumour cells. Expert Opin Biol Ther. 2005;5(4):443-449.

30. Curtiss R 3rd, Kelly SM. Salmonella typhimurium deletion mutants lacking adenylate cyclase and cyclic AMP receptor protein are avirulent and immunogenic. Infect Immun. 1987;55(12):3035-3043.

31. Belyakov IM, Ahlers JD. What role does the route of immunization play in the generation of protective immunity against mucosal pathogens? J Immunol. 2009;183(11):6883-6892. 
32. Martinoli C, Chiavelli A, Rescigno M. Entry route of Salmonella typhimurium directs the type of induced immune response. Immunity. 2007;27(6):975-984.

33. Feltis BA, Miller JS, Sahar DA, et al. Liver and circulating $\mathrm{NK} 1.1(+) \mathrm{CD} 3(-)$ cells are increased in infection with attenuated Salmonella typhimurium and are associated with reduced tumor in murine liver cancer. J Surg Res. 2002;107(1):101-107.

34. Pawelek JM, Low KB, Bermudes D. Tumor-targeted Salmonella as a novel anticancer vector. Cancer Res. 1997;57(20):4537-4544.
35. Gentschev I, Fensterle J, Schmidt A, et al. Use of a recombinant Salmonella enterica serovar Typhimurium strain expressing C-Raf for protection against C-Raf induced lung adenoma in mice. BMC Cancer. 2005;5:15.

36. Clairmont $\mathrm{C}$, Lee $\mathrm{KC}$, Pike J, et al. Biodistribution and genetic stability of the novel antitumor agent VNP20009, a genetically modified strain of Salmonella typhimurium. J Infect Dis. 2000;181(6):1996-2002.

37. Toso JF, Gill VJ, Hwu P, et al. Phase I study of the intravenous administration of attenuated Salmonella typhimurium to patients with metastatic melanoma. J Clin Oncol. 2002;20(1):142-152.

\section{Publish your work in this journal}

Biologics: Targets \& Therapy is an international, peer-reviewed journal focusing on the patho-physiological rationale for and clinical application of Biologic agents in the management of autoimmune diseases, cancers or other pathologies where a molecular target can be identified. This journal is indexed on PubMed Central, CAS,

\section{Dovepress}

EMBase, Scopus and the Elsevier Bibliographic databases. The manuscript management system is completely online and includes a very quick and fair peer-review system, which is all easy to use. Visit http://www.dovepress.com/testimonials.php to read real quotes from published authors.

Submit your manuscript here: http://www.dovepress.com/biologics-targets--therapy-journal 